LA W RENCE LIVERMORE NATIONAL LABORATORY

\title{
Detecting and monitoring UCG subsidence with InSAR
}

R. J. Mellors, W. Foxall, X. Yang

March 26, 2012 
This document was prepared as an account of work sponsored by an agency of the United States government. Neither the United States government nor Lawrence Livermore National Security, LLC, nor any of their employees makes any warranty, expressed or implied, or assumes any legal liability or responsibility for the accuracy, completeness, or usefulness of any information, apparatus, product, or process disclosed, or represents that its use would not infringe privately owned rights. Reference herein to any specific commercial product, process, or service by trade name, trademark, manufacturer, or otherwise does not necessarily constitute or imply its endorsement, recommendation, or favoring by the United States government or Lawrence Livermore National Security, LLC. The views and opinions of authors expressed herein do not necessarily state or reflect those of the United States government or Lawrence Livermore National Security, LLC, and shall not be used for advertising or product endorsement purposes.

This work performed under the auspices of the U.S. Department of Energy by Lawrence Livermore National Laboratory under Contract DE-AC52-07NA27344. 


\title{
Detecting and monitoring UCG subsidence with InSAR
}

\author{
R. Mellors, B. Foxall, and X. Yang
}




\section{Table of Contents}

1.0 Summary

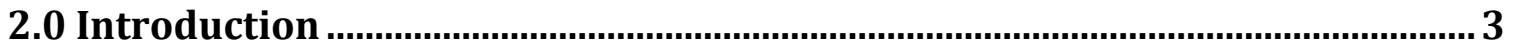

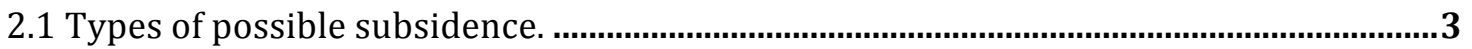

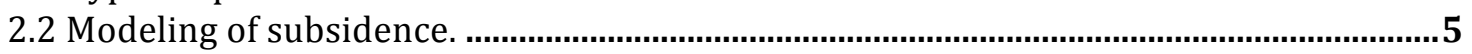

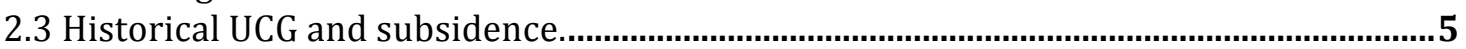

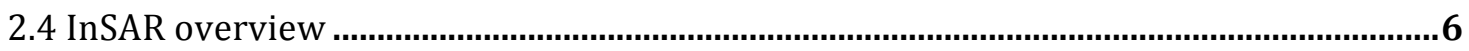

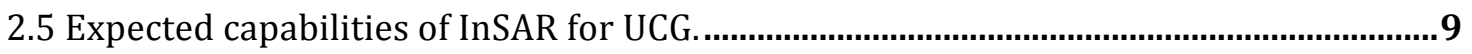

3.0 Observations of UCG areas with InSAR ............................................................... 10

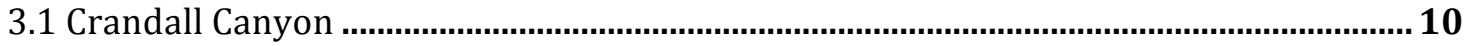

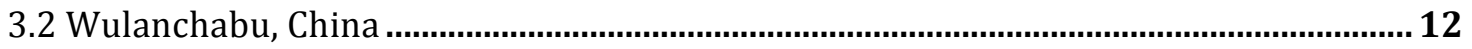

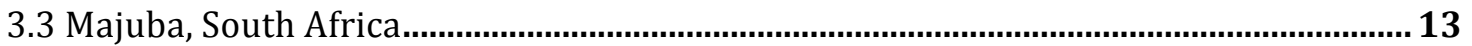

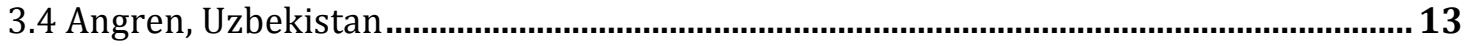

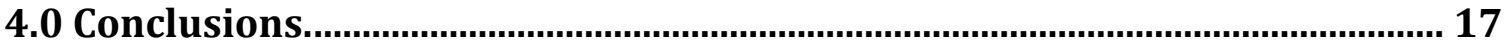

4.0 References.

\subsection{Summary}

The use of interferometric synthetic aperture radar (InSAR) to measure surface subsidence caused by Underground Coal Gasification (UCG) is tested. InSAR is a remote sensing technique that uses Synthetic Aperture Radar images to make spatial images of surface deformation and may be deployed from satellite or an airplane. With current commercial satellite data, the technique works best in areas with little vegetation or farming activity. UCG subsidence is generally caused by roof collapse, which adversely affects UCG operations due to gas loss and is therefore important to monitor. Previous studies have demonstrated the usefulness of InSAR in measuring surface subsidence related to coal mining and surface deformation caused by a coal mining roof collapse in Crandall Canyon, Utah is imaged as a proofof-concept. InSAR data is collected and processed over three known UCG operations including two pilot plants (Majuba, South Africa and Wulanchabu, China) and an operational plant (Angren, Uzbekistan). A clear feature showing approximately $7 \mathrm{~cm}$ of subsidence is observed in the UCG field in Angren. Subsidence is not observed in the other two areas, which produce from deeper coal seams and processed a smaller volume. The results show that in some cases, InSAR is a useful tool to image UCG related subsidence. Data from newer satellites and improved algorithms will improve effectiveness. 


\subsection{Introduction}

Underground Coal Gasification (UCG) is a promising technology capable of extracting gas from sub-surface coal deposits [Couch, 2009; Shafirovich and Varma, 2009]. In some conditions, UCG operations have caused varying degrees of surface subsidence. Monitoring this subsidence is essential for avoiding damage to nearby infrastructure and for providing essential information about the state of the subsurface [Burton et al., 2007; Mellors et al., 2011; Yang et al., 2011]. This information includes the possibility of tracking the burn front as well as unexpected sub-surface events, such as extensive roof collapse that may propagate upwards into shallower layers [Gregg, 1977]. As shallower layers may contain aquifers, tracking of these collapse events is vital to ensure containment of UCG products.

Subsidence can be monitored using ground-based or space-based methods. Ground-based methods may be survey-based or require emplacement of instrumentation. Surveys include optical leveling, Global Positioning System (GPS) measurements, or LiDAR. Ground-based instrumentation usually consists of tiltmeters or strainmeters. Space-based interferometric synthetic aperture radar (InSAR) has proven effective in measuring subsidence over wide areas. In this report the effectiveness of InSAR for resolving subsidence due to UCG operations is assessed.

\subsection{Types of possible subsidence}

In general, the pattern of subsidence from UCG operations resembles subsidence caused by coal mining. In this work, the term 'subsidence' is reserved for surface deformation and refers to primarily downward vertical deformation but may include some horizontal displacement as well. The primary factors influencing subsidence are the width, thickness and depth of the excavation. Other factors, such as type of overburden, void geometry, subsurface heterogeneities, surface topography, and the stress field may influence the pattern and amplitude of deformation as well.

The underlying cause of surface subsidence is subsurface roof and chamber failure, either by collapse or bending. This displacement propagates upward and creates surface subsidence. The resulting surface displacements typically appear as either steep-sided collapse features (sinkholes) or as a downward bending of the surface (troughs). Surface subsidence due to collapse may be concurrent with mining or delayed in time and occur years after the initial excavation. Delays of a year or more are more common with deeper $(>250 \mathrm{~m})$ mines [Whitaker and Reddish, 1989]. If sub-surface roof collapse does not occur, very little surface 
subsidence will be observed. Therefore, if the UCG operation end-result is a series of chambers separated by thick walls, as occurs in room-and-pillar coal mining, little surface subsidence is expected. If the chambers merge over time then the surface subsidence may resemble the effects of longwall coal mining except that the roof collapse may occur more gradually.

The most common type of roof failure is spalling of rock from the roof into the chamber. Spalling is expected to be more prevalent for UCG operations than in coal mining due to the drying out and thermal cracking caused by the heat of the combustion. For single chambers, spalling will continue until a stable arched roof forms [Gregg, 1977]. For larger chambers formed by the possible merging of closelyspaced UCG chambers, spalling may progress into complete roof collapse, in which the failure continues until the chamber fills with rubble. In mining, subsidence can also be caused by pillar collapse. Flooding of cavities after extraction is completed may lead to collapse if clays and mudstones are prevalent in the surrounding rock.

The height of the chamber formed by spalling is generally 2 to 10 times the original cavity height. Unless the spalling breaks through to the surface, the surface expression will appear as a trough [Gregg, 1977] due to bending and fracturing of the overburden above the collapse. The amplitude of the trough depends on the depth and type of overburden as well as the height of the chamber. The spatial extent of surface deformation is wider than the sub-surface chamber and the extent is defined by the angle of draw (Figure 1), which varies from 10 to 50 degrees, depending on the overburden [Betourney, 2011].

A less common, but more unpredictable type of roof failure is chimneying, which is progressive failure by spalling confined to a small area and which may occur at a high rate (10's of meters per day). Chimneying was observed in Soviet era UCG operations and was especially prevalent in steeply dipping beds [Gregg, 1977]. Chimneying may also occur in faulted rocks. Another type of subsidence is bending subsidence, in which the overburden sags or bends into cavern. Pillars 'punching' into a soft (possibly clay) floor may also cause downward bending of the roof, which may eventually progress into roof collapse.

Subsidence presents multiple hazards to UCG operations. From an operational view, roof collapse during burns will likely adversely impact process efficiency by plugging the chamber. Roof collapse or severe upward fracturing may also allow hot gases to permeate into shallower layers resulting in gas loss, which reduces efficiency. The shallow layers may contain aquifers and result in environmental impact. Finally, excessive subsidence or sinkhole formation at the surface may damage nearby infrastructure. Careful monitoring of subsidence may allow remediation of effects or an understanding of likely fracture patterns. It may be possible to predict where tensile fractures, which tend to be more permeable, may occur. 


\subsection{Modeling of subsidence.}

Historically, the primary approach in modeling subsidence has been to match the observed subsidence using empirically or semi-empirically derived equations

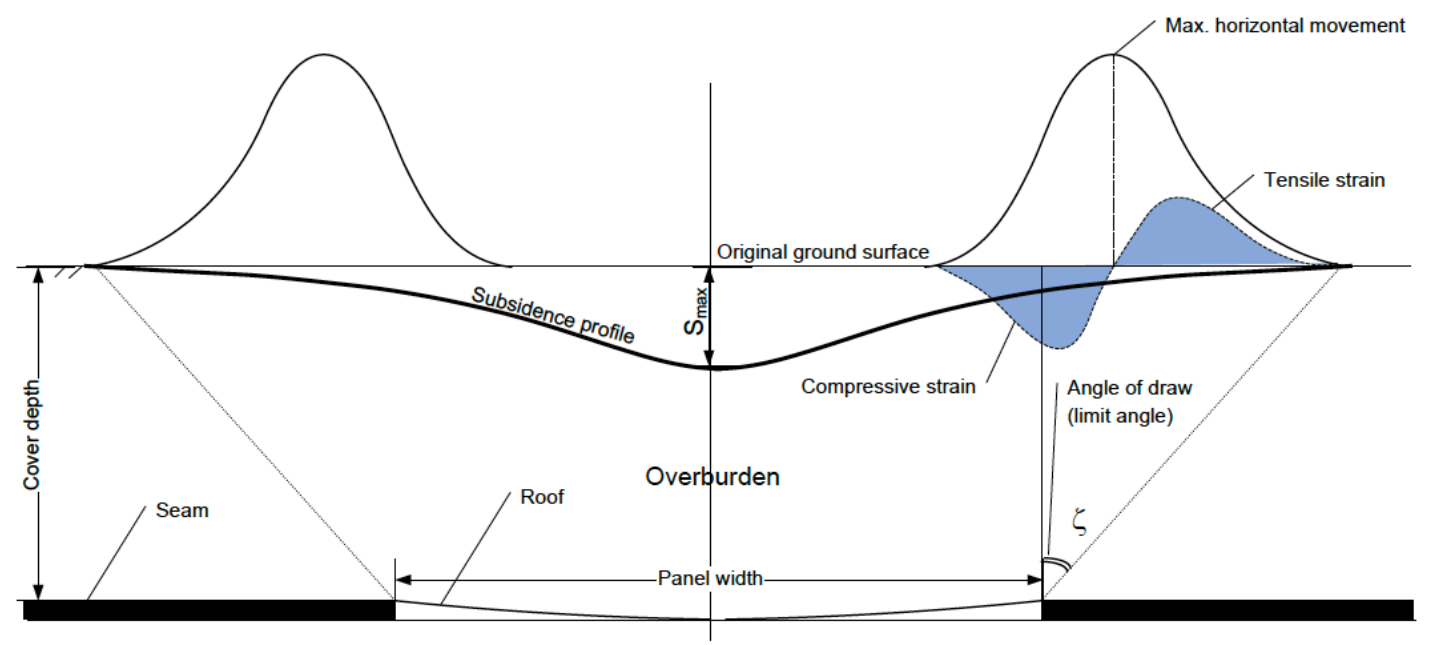

Figure 1. Mining subsidence terminology and typical surface expression. From Ren and Li, [2008].

[e.g. NCB, 1975]. Physical models have also been used. More recently, direct numerical modeling of the subsurface has been applied.

Profile functions predict subsidence by using a defined equation combined with empirically determined constants. For any given area, existing subsidence is measured and the appropriate factors estimated by curve-fitting. The factors are then used to predict future subsidence. Influence functions attempt to define the pattern of subsidence on the surface from an infinitesimal extraction element. The overall surface subsidence can be estimated by linear combinations of the extraction elements. The exact shape of the influence function can be determined empirically. Often, two 'bounding estimates' may be generated to accommodate uncertainties.

Numerical modeling can be effective but requires exact material properties for accurate estimation. As rocks may behave in a non-linear fashion, even small inaccuracies may have a significant influence on the accuracy of the results. Localized subsidence can be difficult to predict.

\subsection{Historical UCG and subsidence}

The majority of industrial-scale UCG production efforts were undertaken in the Soviet Union. Here we summarize the work of Gregg [1977]. In horizontal seams, the gasification was conducted on a grid with series of boreholes for air injection and gas withdrawal spaced $25 \mathrm{~m}$ apart. At one UCG site, Podmoskovnaya, the coal seam (lignite) averaged $2.7 \mathrm{~m}$ thick at a depth of 48 meters. The overburden primarily consisted of clays and sands. As the gasification was conducted, 
subsidence occurred immediately after the gasification in a relatively slow manner ( $<60 \mathrm{~mm}$ /day). The total amount approached $\sim 1.2 \mathrm{~m}$ at the surface but increased with depth. The total subsidence at depth was slightly less than the original seam thickness. The subsidence rate appeared to track the gasification rate and was used to track the burn front. Later excavation showed that no cavities larger than 1 meter existed in the subsurface and the rapid subsidence was inferred to be due to the weak overburden.

At the Lisichansk and the Yuzhno-Abinsk sites, the coal layers were steeply inclined but differed in thickness at the two sites. Lisichansk was less than $1.5 \mathrm{~m}$ thick and Yuzhno-Abinsk was up to 9 meters thick. Overburden consisted of shales, sandstone, and limestone. At Lisichansk little subsidence was observed and appeared to correlate to that expected by bending subsidence. Bending subsidence also occurred at Yuzhno-Abinsk but was accompanied by intermittent chimneying and sinkhole formation up the steeply dipping coal beds and overburden. The collapse caused considerable gas leakage.

As many modern operations have operated only at the test-bed and pilot scale level, significant subsidence was not expected or measured [Burton et al., 2007]. A subsidence event occurred at Hoe Creek but the hole was relatively small (meters in diameter) with steep sides.

\subsection{InSAR overview}

Synthetic Aperture Radar (SAR) is an active imaging technique that uses microwave length electromagnetic energy to create back-scatter images of the earth's surface from a moving antenna. By accumulating radar echoes over a time period and post-processing the data high-resolution images can be created [Curlander and McDonough, 1988]. Interferometric SAR (InSAR) refers to using phase differences between pairs of images to image displacement of the ground surface and surface motion from a wide variety of causes, both natural (e.g. earthquakes, glaciers) and anthropogenic (e.g. groundwater or hydrocarbon extraction, mining), have been imaged [e.g. Massonnet and Feigl, 1998]. Typical platforms are satellites or airplanes. Recently, ground-based units have become available. In this study we examine the use of using commercial SAR data from satellites to image ground displacement from underground coal gasification.

Before interferometry is applied, SAR images must be created from raw data. Unlike optical remote sensing, SAR images require processing to create an image. In standard image mode, a radar pulse encoded as a chirp on the carrier frequency is sent continuously at a high rate during image acquisition. This pulse then reflects off the surface and the resulting reflections are combined, after considerable processing, into an image. Both the amplitude and the phase of the returning signal

area measured. A variety of acquisition modes with differing characteristics exist 
(e.g. scansar, spotlight). For additional details see Curlander and McDonough, [1988].

Common commercial satellites operate at one of several wavelengths: $2 \mathrm{~cm}$ (X-band), $5.23 \mathrm{~cm}$ (C-band), and $23 \mathrm{~cm}$ (L-band). Typical resolution is on the order of 10-20 m but depends also on exact acquisition and processing. Reflection strength, phase, and polarization depend mainly on the geometry and electromagnetic properties of the surface. In general, surfaces with irregularities on the order of the radar wavelength will reflect more signal energy back to the satellites and show higher average amplitudes. The amplitude and phase of each pixel is an average of all the reflecting surfaces in the pixel. A special case is a point scatterer that returns a very strong (amplitude) signal and is much stronger than other scatterers within a specific pixel. Point scatters are most commonly the results of anthropogenic structures but can also occur naturally.

The phase of the signal depends on the reflecting surface but is also slightly altered by the transmission through the atmosphere, both in the ionosphere as a result of variations in electron density and in the troposphere by water vapor. Ionosphere effects are more pronounced for longer wavelengths. Variations in water vapor can cause pronounced artifacts. Atmospheric effects vary with time and hence can be distinguished from surface motion by examining multiple images over time.

InSAR uses the relative difference in phase between two images of the same area to measure topography or to detect change. In this study, two images of the same region acquired at different times are differenced to measure phase change caused by surface displacement during the intervening period. The measurement (range change) is along the line of sight to the satellites. Images must be aligned at the pixel level. This method requires that the relative phase change between adjacent pixels remain similar (correlated) for each image. By differencing the two images, the result yields the change in phase during the intervening period. If the relative phase of each pixel varies independently in each image, the pixels are uncorrelated and the measurement is meaningless. The relative phase between pixels also depends on the satellite and surface geometry, atmospheric effects, variations in surface electromagnetic response, and noise. If the satellite and surface position is sufficiently accurate, the geometric corrections can be calculated and removed. This requires accurate knowledge of the satellite position (orbit) and surface (topography). Interferograms can only be calculated when the two satellites are within a certain distance, known as the baseline, of each other. This distance depends on the wavelength. The sensitivity to the topography increases with baseline and in particular, the component perpendicular to the surface of the earth.

The resulting difference image is known as an interferogram. As the difference is estimated between complex numbers and then converted to a real number representing phase using the inverse tangent, the result is modulo( $2 \pi)$ or 'wrapped'. In most case this image must be unwrapped to convert to a continuous 
function. Unwrapping the phase can be difficult for large signals or images with large amounts of uncorrelated data.

Extracting the signal from noise can be challenging in the case of small signals due to the variety of possible errors. The errors do differ in spatial and temporal frequency and can often be reduced with processing but not eliminated. If a number of images over a specific area are available, it is possible to construct a time series and increase signal resolution. This is becoming more common as the amount of potentially useful data increases and several techniques exist to analyze time series.

The along-sight change resolution depends on radar wavelength and signal quality, which varies greatly. For a single pair of images, resolution along the line-ofsight is roughly a fraction of the radar wavelength, which depends on the particular satellite. For data available now, radar wavelengths are $2 \mathrm{~cm}$ (X-band), $5.23 \mathrm{~cm}$ (Cband), and $23 \mathrm{~cm}$ (L-band). For the technique to work, the signal must be correlated between the two scenes. Movements greater than one wavelength over a distance less than one pixel will be decorrelated. Significant changes in backscatter will decorrelate the signals and prevent measurement. Decorrelation typically increases with time and the rate varies with the wavelength. L-band images decorrelate less quickly than $\mathrm{C}$ band. Factors influencing decorrelation include vegetation, farming, and rainfall (or snow).

An important caveat is that the information from an interferogram measures only one vector direction of displacement, which depends on the satellite look angle and track (ascending or descending, which refers to the satellite motion with respect to the North Pole). As SAR satellites are in polar orbits, the satellite tracks are slightly (e.g. 12 degrees) inclined with respect to a north-south line. Look angles are more variable but are generally in the 20 to 40 degree range. This geometry means that a measurable range change may be caused by either vertical or horizontal east-west motion, although the measurements are more sensitive to vertical motion. To distinguish between vertical and east-west motions data from two different tracks (ascending and descending) are needed. North-south horizontal motion is essentially impossible to resolve with conventional methods.

Several different approaches have been suggested to reduce error using multiple interferograms and this is an active area of research. The simplest method is to simply average, or stack the data. If the noise is random and normal, stacking is expected to reduce the noise by a factor of $\operatorname{sqrt}(\mathrm{N})$, where $\mathrm{N}$ is the number of interferograms. Unfortunately, noise in interferograms is not normally distributed and hence stacking is not always effective. For large numbers of interferograms (> 20 ), stacking usually improves the signal to noise for temporally varying noise such as thermal or atmospheric. An iterative approach, in which images that are heavily contaminated by atmospheric effects, as determined by comparison with the initial stack, can be effective in identifying poor quality scenes. The advantage of stacking is that no assumptions about the signal characteristics are required. Typically, the 
error in the range change resolution is on the order of one $\mathrm{cm}$ with a sufficient number of images ( $>20)$ in areas with good coherence and moderate topography.

Another approach, short baseline or SBAS (Small Baseline Subset), uses only interferograms with short baselines that can be successfully unwrapped prior to application of the algorithm. This reduces the sensitivity to topographic error and increases the quality of the interferograms. Typically, one pixel is designated as stable and a combined filtering/inverse approach is used to extract the signal and distinguish it from other source such as atmospheric or topographic [Berardino et al., 200]. A disadvantage is that strongly non-linear signals (non-linear in time) are often poorly resolved. Range change resolution on the order of $\mathrm{mm}$ has been achieved with this method after comparison with ground truth.

A third approach [Ferretti et al., 2001] attempts to define specific pixels whose phase is primarily contributed by one specific scattering point. These points, known as persistent scatterers (PS), retain phase coherence with respect to other, spatially distance persistent scatterers even at long baselines and over long time periods. Once identified, these points can be used as a basis for a filtering and inverse scheme to resolve displacements. This method does not require unwrapping but does require identification of sufficient pixels, which is usually done on the basis of amplitude. If a sufficient density of scatterers is available, resolution is usually better than the SBAS technique as more interferograms are available. More recently, work is being done to identify stable pixels using a statistical approach [e.g. Hooper et al. 2008]. The commercial company TRE possesses a proprietary algorithm that has shown good results over mining areas using a time series approach.

\subsection{Expected capabilities of InSAR for UCG}

Given the expected signals from UCG associated subsidence and known InSAR capabilities, a rough assessment of the use of InSAR for UCG can be conducted. The minimum signal size (spatial) that can be reliably measured should span several pixels and hence the signal should exceed $50 \mathrm{~m}$ spatially for most commonly used geometries (i.e. larger for ScanSAR but smaller for spotlight mode). If the target area happens to include a point scatterer either by accident or intent (e.g. corner reflector) it would be possible to measure the displacement of the corner reflector directly. The range change resolution also depends on the signal quality and wavelength but in general, at least $5 \mathrm{~mm}$ of line-of-sight displacement is required to produce an unambiguous signal. For most satellite geometries, this infers roughly $1 \mathrm{~cm}$ of vertical displacement. If a time series approach is applied, which requires a series of repeat measurements over the same area, it is expected that line-of-sight resolution might approach 1-2 mm.

Signals of this magnitude are easily caused by coal mining operations and have been reported for commercial scale UCG operations, as noted above. Small (tens of $\mathrm{m}$ ) pilot plant type UCG tests at depths greater than $100 \mathrm{~m}$ are unlikely to 
create measurable signals unless accompanied by collapse. In this work, we report on InSAR surveys of three active (or formerly active) UCG areas and one coal mining area. Data is either purchased or provided by a research consortium. Two InSAR packages are installed and available. These are the commercial GAMMA package and an open source package (GMTSAR), [Sandwell et al., 2011]. Both these packages possess some time series capability.

\subsection{Observations of UCG areas with InSAR}

As the number of active UCG areas is limited, it is useful to first review the use of INSAR over coal mining areas and then selected UCG sites. A number of studies have used InSAR to examine subsidence from coal mines [e.g. Cao et al., 2008; Ng et al., 2009; Perski, 1998; Perski amd Jura, 2003; Stow and Wright, 1997].

$\mathrm{Ng}$ et al., [2010] examined subsidence over the West Cliff colliery in the Sydney basin of Australia. It is a mine at a depth of 470-540 m that extracted a 2.2$2.8 \mathrm{~m}$ thick coal seam using longwall mining with panels approximately $305 \mathrm{~m}$ wide. Typical surface subsidence after roof collapse was $\sim 1 \mathrm{~m}$. Using multiple ALOS PALSAR (L-band) images including ascending and descending, the 3D vector deformation was resolved using different look angles with an estimated error level of less than $1 \mathrm{~cm}$. Measurements were validated using GPS. Atmospheric errors were assumed minimal and less resolution was achieved in the north-south direction. Similar results should be possible for large-scale UCG operations.

\subsection{Crandall Canyon}

As a validation of InSAR processing here, a set of images was acquired over the Crandall Canyon mine in Utah, where a collapse in August 2007 produced a clear signal [Lu and Wicks, 2010; Plattner et al., 2010]. Although Crandall Canyon is not a UCG operation, it is useful to examine as a proof of the concept. The collapse occurred during room and pillar operations at a depth of about $600 \mathrm{~m}$ in a seam with a thickness of about $2.4 \mathrm{~m}$. Plattner et al., [2010] conducted modeling of the signal using a variety of methods and concluded that elasto-plastic collapse of an elliptic cavity provided the best fit to the data. Seismic data was also considered. 


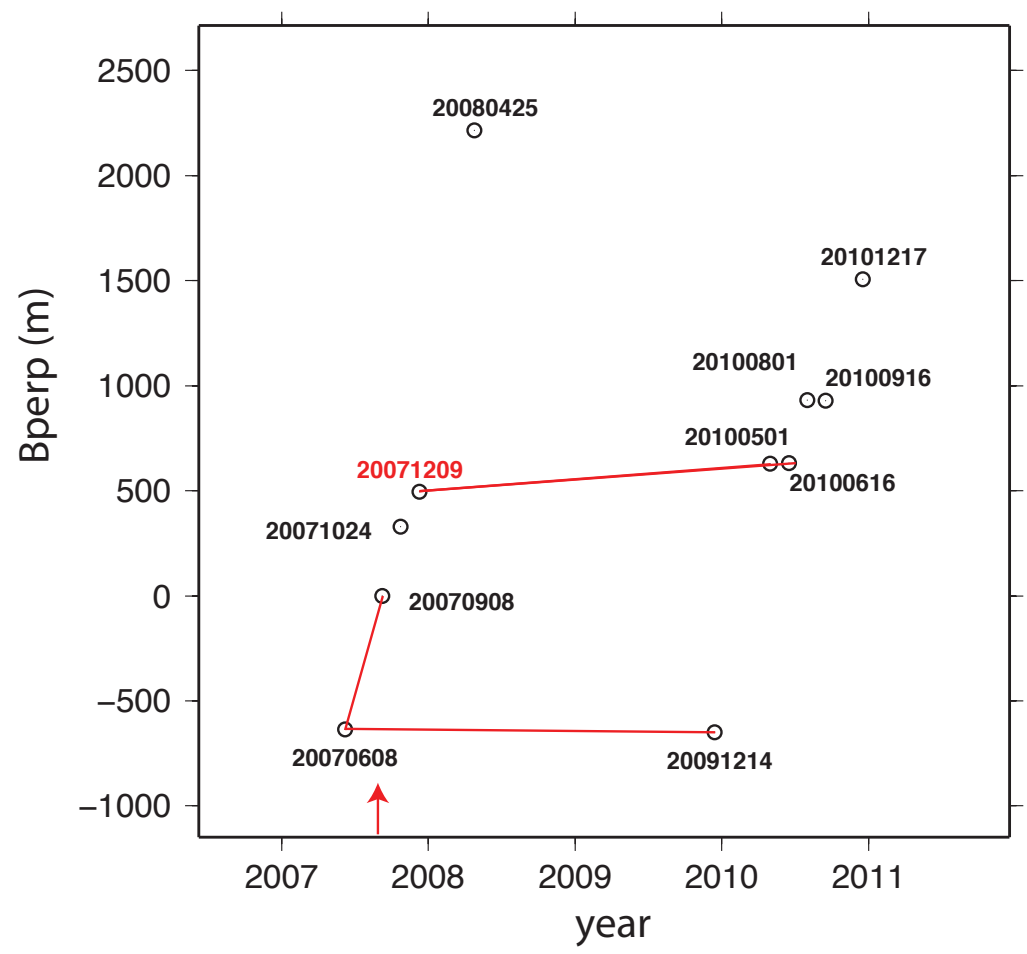

Figure 2. ALOS (ascending) data available for the Crandall Canyon mine collapse. Red lines indicate selected interferograms.

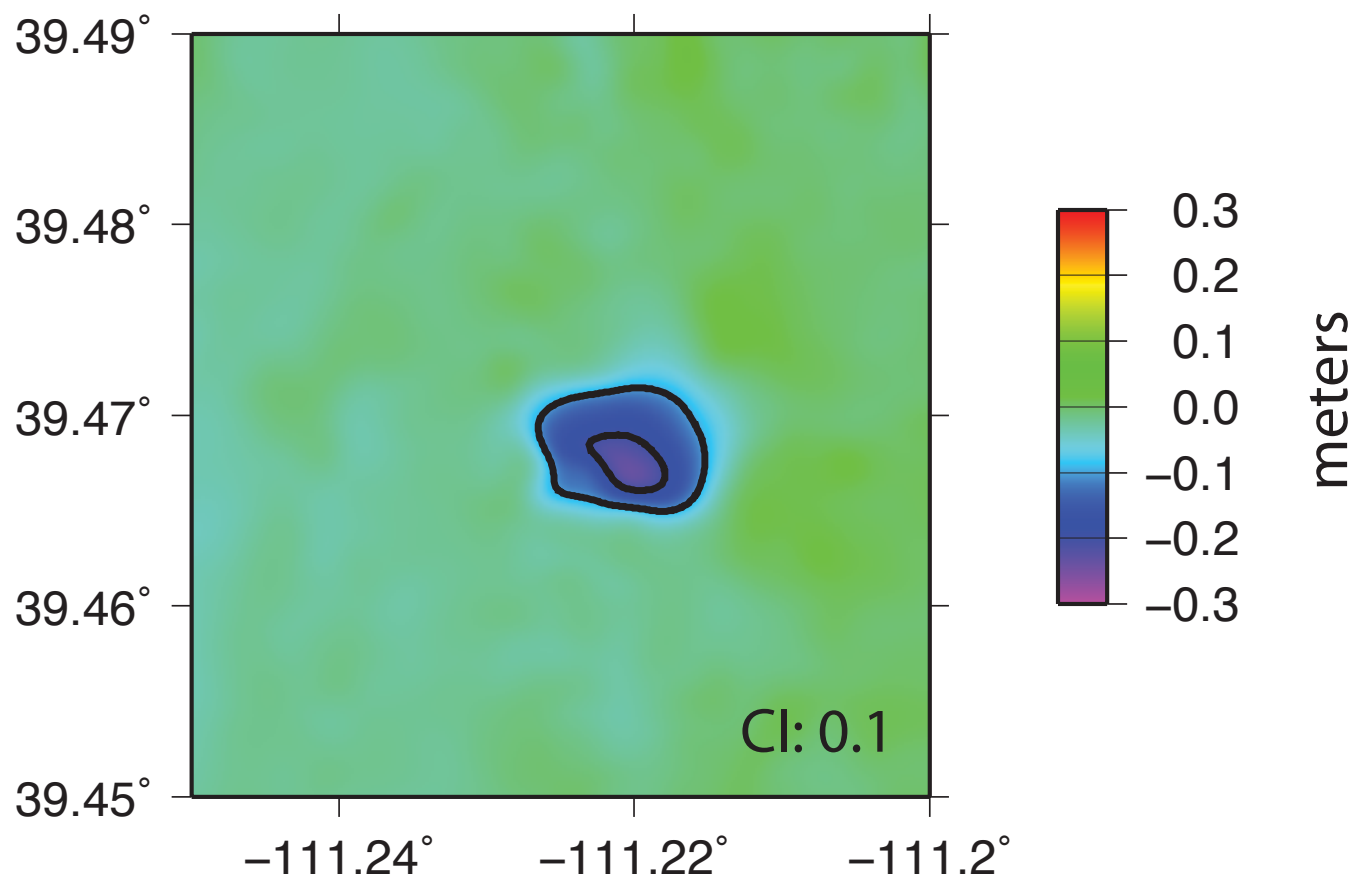

Figure 3. Map view of deformation associated with Crandall Canyon collapse. Contour interval is 0.1 $\mathrm{m}$. Displacement is equivalent vertical displacement inferred from line-of-sight range change. ALOS PALSAR L-band 6/8/2007 - 12/14/2009. Original SAR data copyright JAXA-METI. 


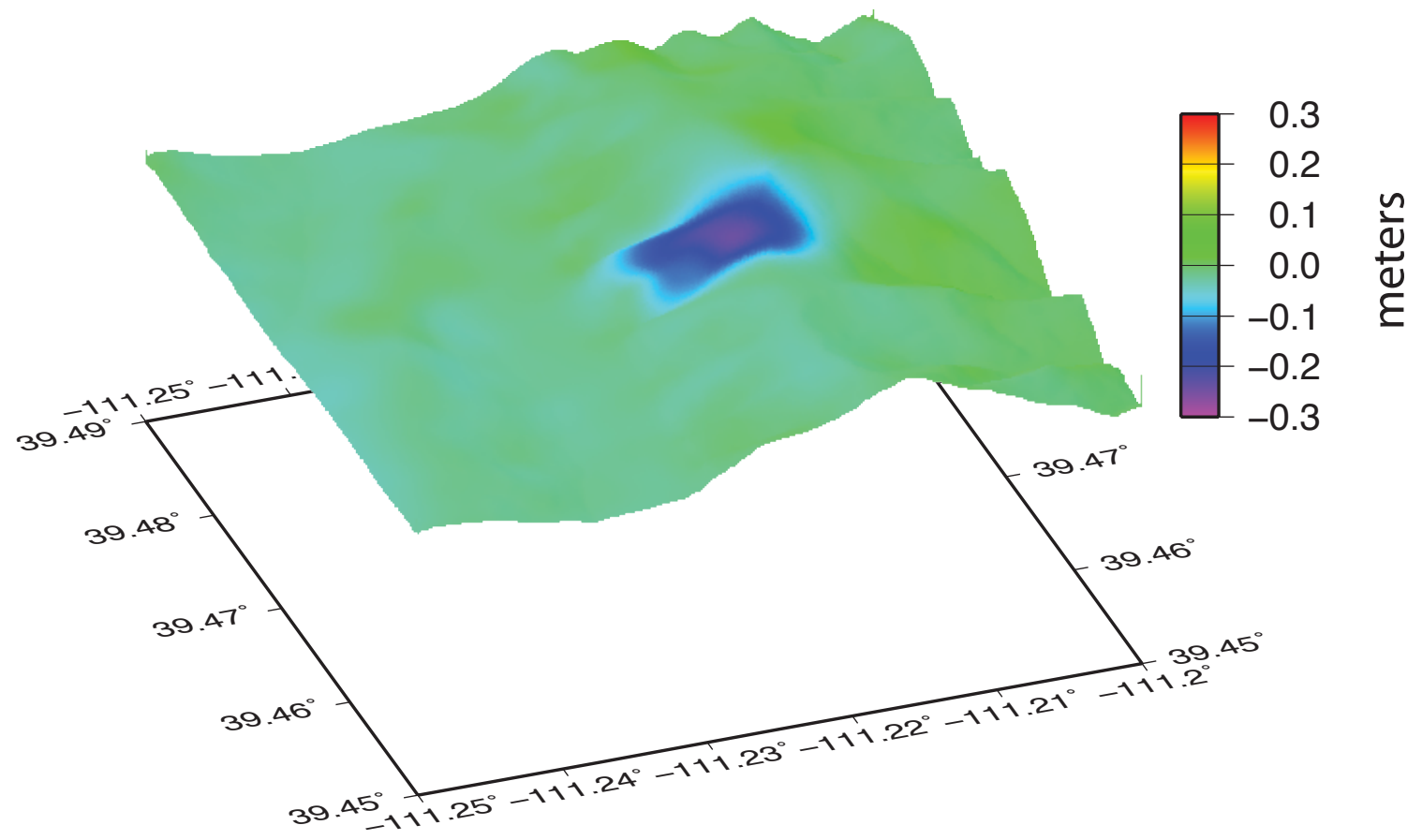

Figure 4. Perspective view of Crandall Canyon collapse draped on topography.

Data for the Crandall Canyon region was acquired from the Western United States InSAR consortium database and consisted of ALOS PALSAR L-band $(23 \mathrm{~cm})$ ascending data. Images were SAR processed and aligned to 2007/12/19 as a master image (Figure 2). NED elevation data used and additional atmospheric correction for high elevation change was applied. A clear deformation signal was observed on an interferogram spanning 8 June 2007 to Dec 14 2009. Despite the longer temporal baseline, this pair possessed the highest coherence and the clearest signal (Figure 3 and 4). The feature was approximately $1 \mathrm{~km}$ in diameter and showed a displacement of $\sim-0.30 \mathrm{~m}$ peak vertical (converted from the line-of-sight range change and assuming pure vertical motion). This is in good agreement with the spatial extent and amplitude reported by Plattner et al. [2010] for the 8 June 2007 - 8 Sept. 2007 pair although the exact details differ slightly. The 8 June - 8 Sept 2007 pair was also processed in this study but showed higher decorrelation, which may have been due to the longer baseline and high elevations. Overall, this demonstrates that the capability to image potential UCG operations exists.

\subsection{Wulanchabu, China}

Five interferograms (2 Envisat C band and 3 ALOS L band) were generated over the UCG site at Wulanchabu. Terrain is flat but decorrelation was significant over longer periods suggesting vegetation or farming. All were of relatively short duration (less than 3 months) so correlation was good but the likelihood of resolving deformation is low. No obvious signals were observed at the location of the UCG plant. 


\begin{tabular}{|l|l|l|l|}
\hline Band & Start & End & Bperp \\
\hline $\mathrm{C}$ & $2 / 1 / 2009$ & $4 / 12 / 2009$ & 145 \\
\hline $\mathrm{C}$ & $3 / 8 / 2009$ & $4 / 12 / 2009$ & 665 \\
\hline $\mathrm{L}$ & $9 / 27 / 2008$ & $11 / 12 / 2008$ & 194 \\
\hline $\mathrm{L}$ & $9 / 16 / 2008$ & $12 / 17 / 2008$ & 515 \\
\hline $\mathrm{L}$ & $12 / 17 / 2008$ & $2 / 1 / 2009$ & 563 \\
\hline
\end{tabular}

\subsection{Majuba, South Africa}

The Mauba site began operations in January 2007 and targeted a 3.5 m thick coal seam at a depth of $300 \mathrm{~m} .9$ ALOS L-band images ranging in time from 2007 to 2009 were acquired and three interferograms were generated. These were chosen due to the short perpendicular baselines $(<350 \mathrm{~m})$. As the region is fairly flat, DEM artifacts are expected to be minimal. Correlation was good. No obvious feature near the location of the UCG operation was observed, suggesting that any surface deformation is small amplitude $(<1 \mathrm{~cm})$ and of limited spatial extent. Given the depth of the operation, seam thickness, and pilot plant scale, the lack of observable signal is not unexpected. A higher resolution would likely be possible with a time series analysis, but given the limited data ( 9 scenes) this was not tested.

\begin{tabular}{|l|l|l|}
\hline Start & End & Bperp $(\mathrm{m})$ \\
\hline $1 / 27 / 2007$ & $7 / 30 / 2007$ & 55 \\
\hline $1 / 27 / 2007$ & $8 / 4 / 2009$ & 279 \\
\hline $7 / 30 / 2007$ & $8 / 4 / 2009$ & 334 \\
\hline
\end{tabular}

\subsection{Angren, Uzbekistan}

The next test was over the commercial UCG "Yerostigaz" program at Angren, Uzbekistan. Angren has been in operation since 1961 and is currently operated by Linc Energy. The source is brown coal at a depth of $\sim 150 \mathrm{~m}$. Production is apparently on the order of $1,000,000 \mathrm{~m} 3$ of syngas per day [http://www.lincenergy.com/acquisitions_yerostigaz.php]. The production is sent via pipeline to a coal-burning power plant approximately $5 \mathrm{~km}$ from the production fields. For a review of Angren geology and operations during the Soviet era see Olness [1982].

ALOS L-band SAR data was acquired via the Alaska SAR facility and interferograms processed using GAMMA (Figure 5). All images were aligned using 070825 as a master and DEM corrections applied using a $30 \mathrm{~m}$ ASTER DEM Secondary atmospheric corrections were applied as a linear phase ramp that correlated with elevation was evident on most interferograms. On the best interferograms (high coherence) several signals were evident. These included subsidence near the open pit coal mine likely due to slumping of the pit sides. Signal was also associated with tailings piles along the side of the valley that may also be 
due to slow slumping. Isolated small large signals occurred near areas of slumping and the area of UCG extraction showed some anomalies.

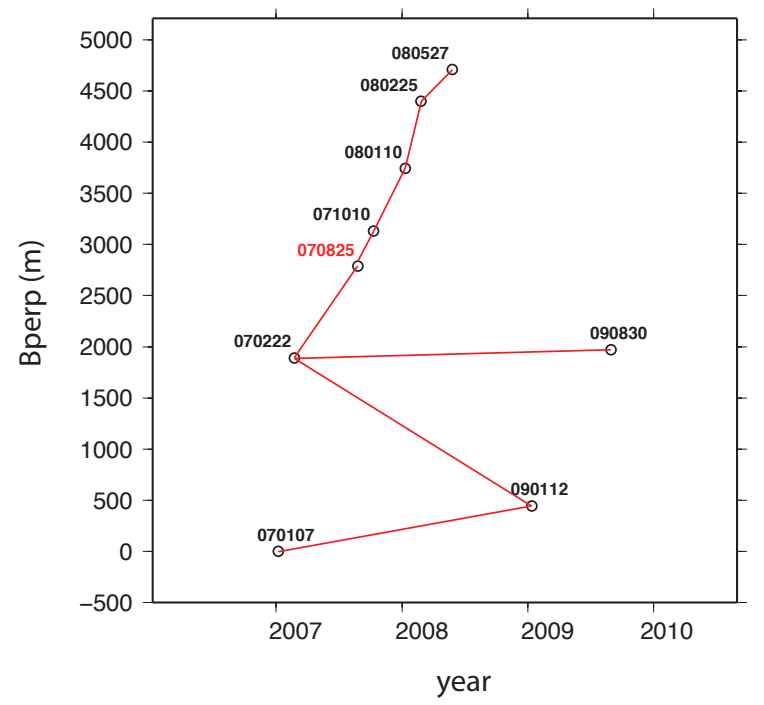

Figure 5. Baseline plot of ALOS L-band data processed for the Angren site. Red lines indicate interferograms.

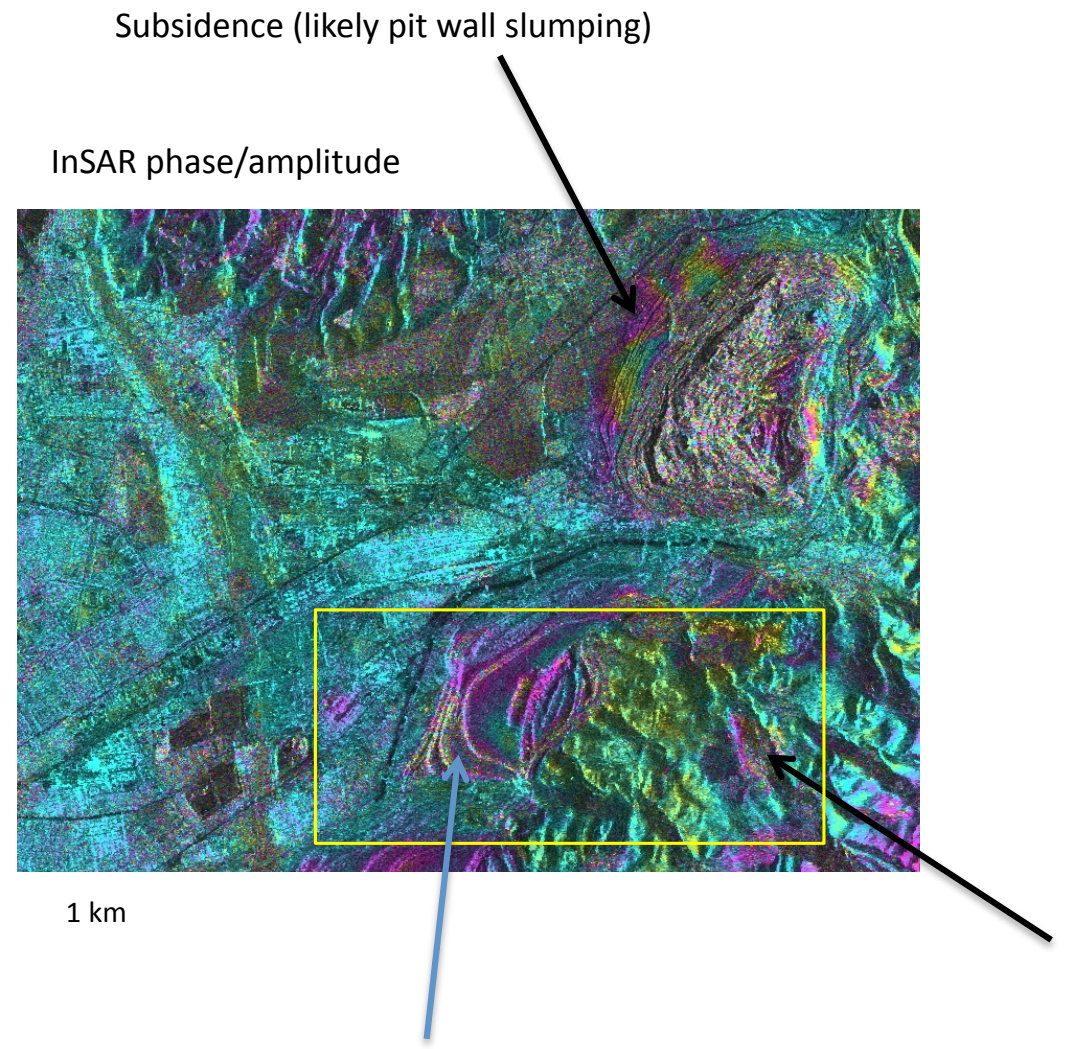

Slumping of tailings from pit?

Figure 6. InSAR interferogram with amplitude as background. ALOS L-band pair spaning July 1, 2007 to Dec 1, 2009. 


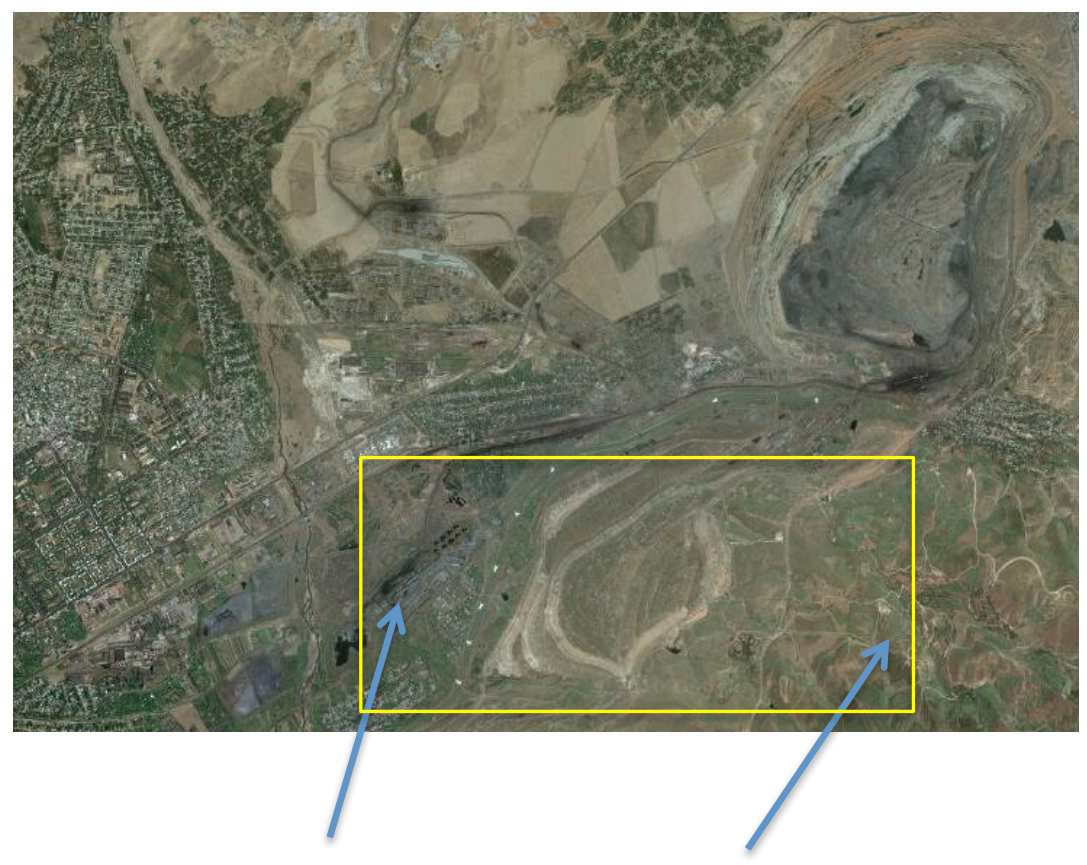

\section{Power station UCG area}

Figure 7. Optical image (Google Earth) of area shown in Figure 6.

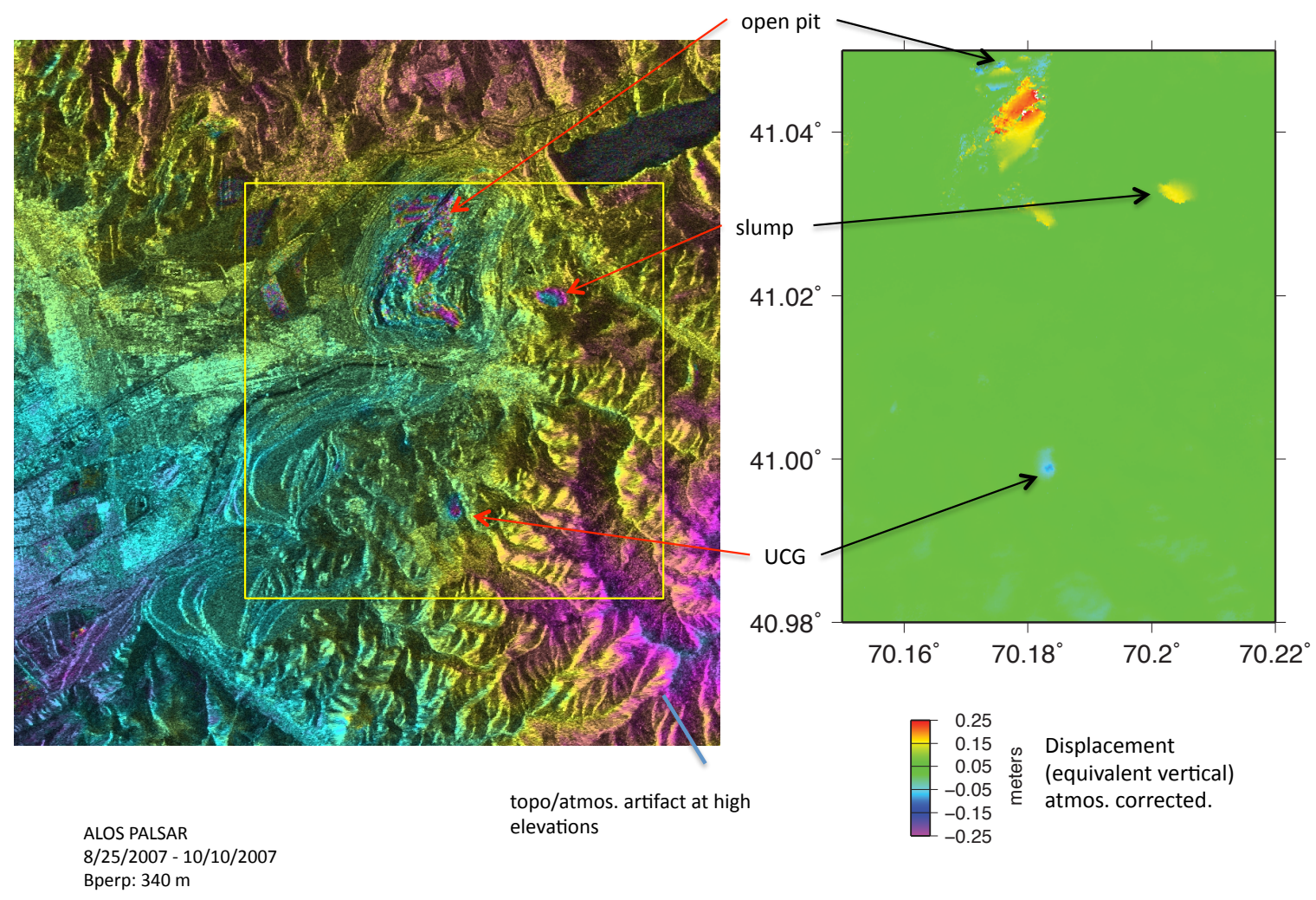

Figure 8. Different interferogram spanning shorter time period showing pit subsidence, isolated slump, and anomaly centered on UCG fields. Figure on left shows phase over intensity while figure on right is phase converted to equivalent vertical displacement. 

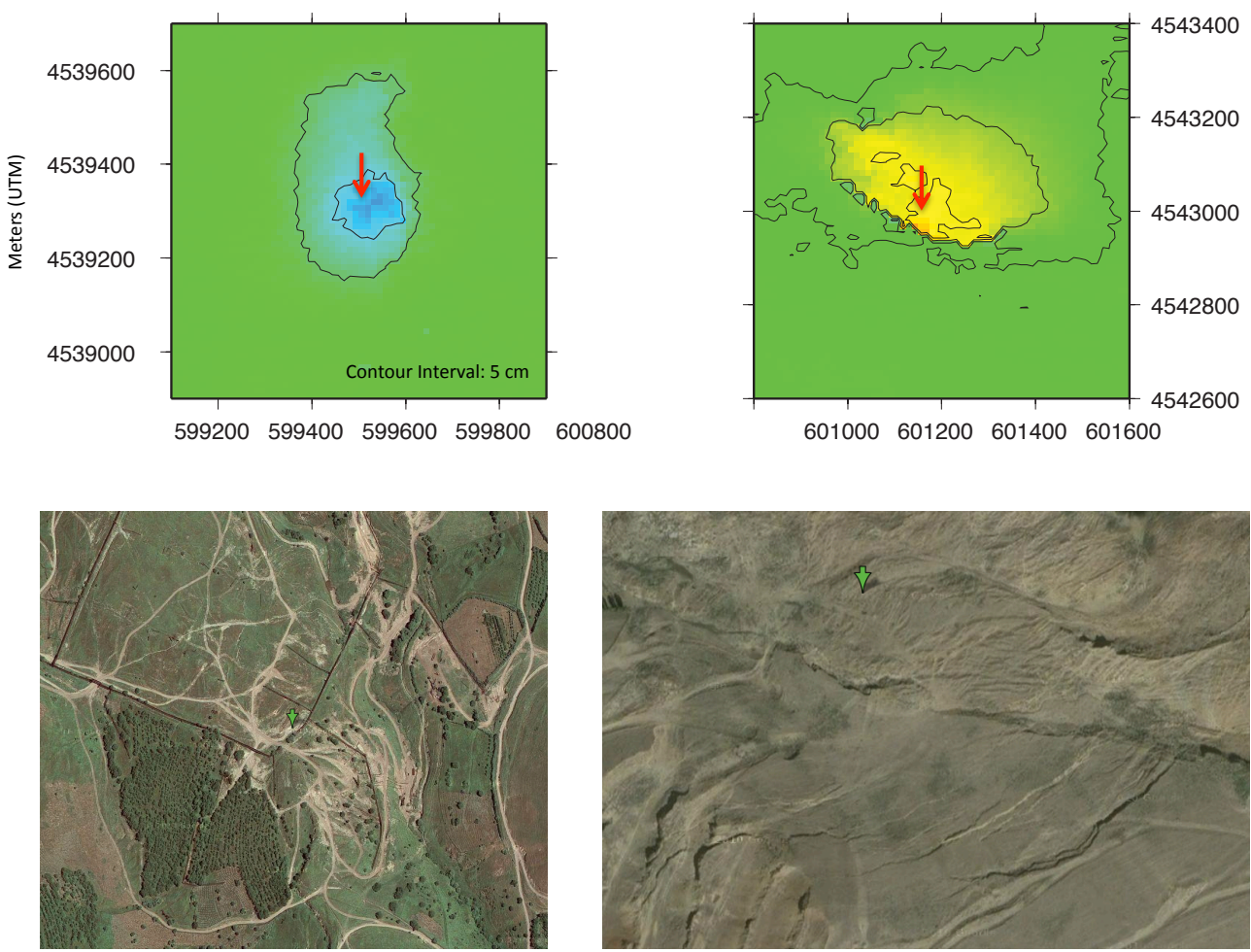

UCG $\quad 70.183061 \mathrm{E} \quad 40.998820 \mathrm{~N}$

Slump 70.203876 E $41.031933 \mathrm{~N}$

Figure 9. Optical (bottom) and InSAR phase (top) of anomalies observed in the 25 Aug 2007 to 10 Oct 2007 interferogram. Displacement is equivalent vertical motion.
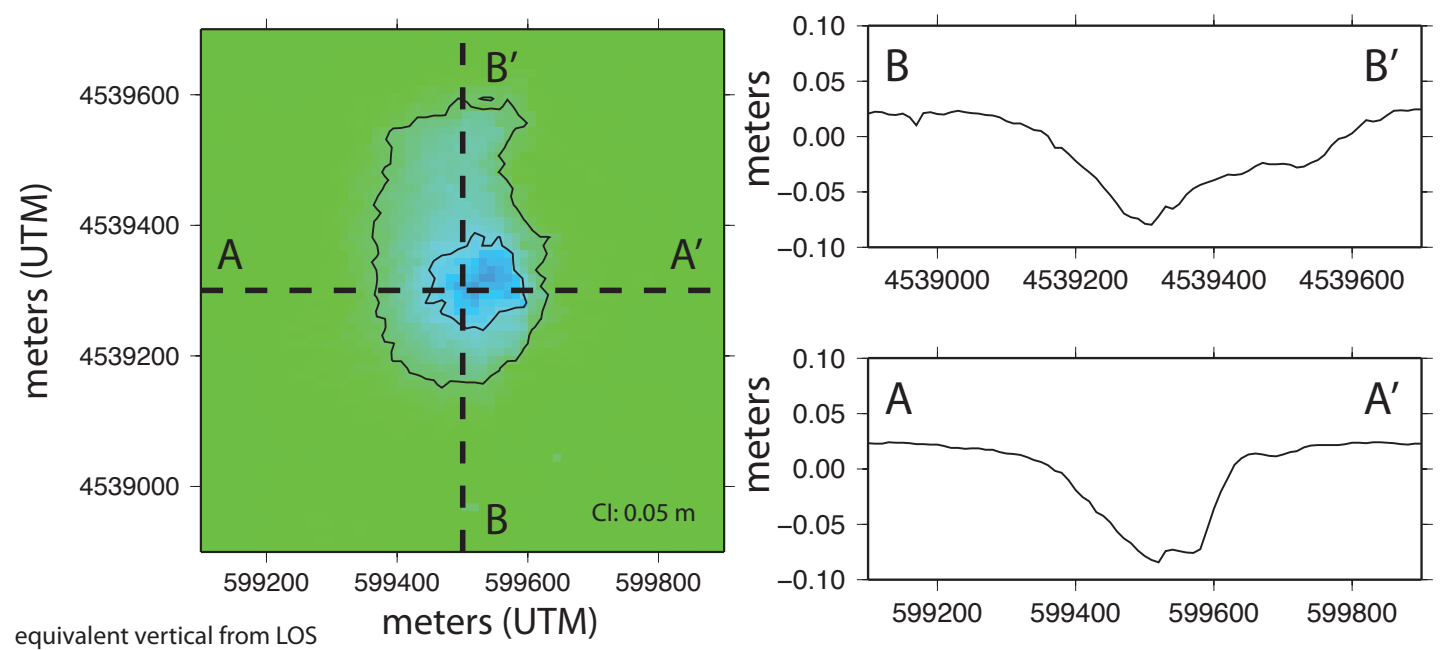

Figure 10. Anomaly centered over UCG production area and likely due to UCG operations. 


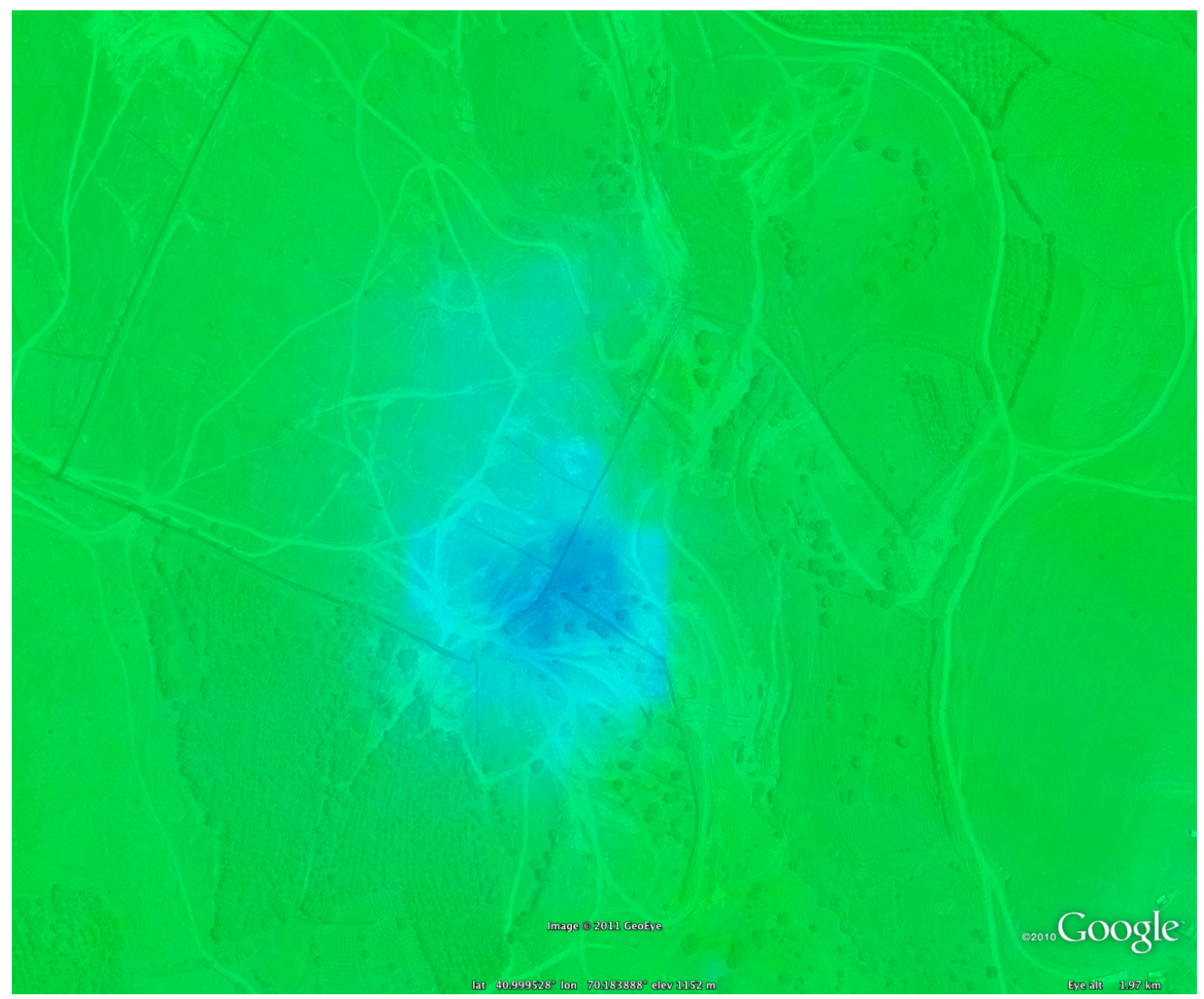

Figure 11. Deformation overlaid over UCG field. Due to different datums, exact location may vary slightly.

\subsection{Conclusions}

This report indicates that InSAR is capable of observing UCG operations in some cases. A clear signal was observed at Angren that coincided with known UCG operations. No signals were observed at other active areas (Majuba in South Africa and Wulanchabu in China). This is likely due to the increased depth and limited (pilot plant) type operation at Wulanchabu and Majuba, as opposed to the relatively shallow and industrial scale Angren UCG work. Differences in geology (e.g. strength of overburden) may have played a role as well.

This study did not specifically task acquisition of the data and was forced to rely on data already collected. This caused relatively poor data coverage (in terms of timing and geometry) for the sites. Most operational use of InSAR for hydrocarbon or ice movement acquires data periodically (once a month, for example) which provides 
much better control. Newer satellites and satellite constellations such as the Italian SkyMed 4 satellite constellation can provide repeat times as short as 4 days.

For using in monitoring ongoing UCG operations, it is likely that a much shorter better temporal resolution is required (on the order of hours), which is unlikely with current and near-future InSAR. In this case, instruments such as tiltmeters would be required. A combination of tiltmeters, with high temporal resolution, and InSAR, with excellent spatial coverage, would be ideal.

This may be the first successful detection of UCG operations using InSAR and suggests that the method has some potential in monitoring subsidence related to UCG. An advantage is the relatively low-cost of the technique, as well as the capability to conduct the monitoring without deploying instrumentation at the site itself.

Acknowledgements. J. Wagoner and S. Hunter provide useful input and the results benefitted greatly from the UCG group. This work performed under the auspices of the U.S. Department of Energy by Lawrence Livermore National Laboratory under Contract DE-AC52-07NA27344. 


\subsection{References}

Bauer, R. A., C. H. Dowding, D. J. Van Roosendaal, B. B. Mehnert, M. B. Su, and K. O'Connor, 1991. Application of Time Domain Reflectometry to Subsidence Monitoring. Office of Surface Mining, Pittsburgh, 48 pp.; NTIS PB 91-228411.

Bell, F. G., J. C. Cripps, M. G. Culshaw and M. A. Lovell, 1988, A review of ground movements due to civil and mining engineering operations, Engineering Geology of Underground Movements, Geological Society Engineering Geology Special Publication No. 5, pp. 3-32.

Betournay, M. C., 2011, Underground Mining and Its Surface Effects, http://www.fhwa.dot.gov/engineering/geotech/hazards/mine/workshops/i awkshp/betourna2.cfm

Berardino, P., Fornaro, G., Lanari, R. and Sansosti, E., 2002. A new algorithm for surface deformation monitoring based on small baseline differential SAR interferograms. IEEE Transactions on Geoscience and Remote Sensing, 40(11): 2375-2383

Burton, E., J. Friedmann, and R. Upadhye, 2007, Best Practices in Underground Coal Gasification. Technical Report. Lawrence Livermore National Laboratory. W7405-Eng-48.

Cao, L., Y. Zhang, J. He, G. Liu, H. Yue, R. Wang, and L. Ge, 2008, Coal Mine Land Subsidence Monitoring by using Spaceborne INSAR Ddata - A Case Study in Fengfeng, Hebei Province, China, The International Archives of the Photogrammetry, Remote Sensing and Spatial Information Sciences. Vol. XXXVII. Part B8. Beijing 2008

Couch, G., 2009, Underground Coal Gasification, p. 129, International Energy Agency Coal Research.

Curlander, J. and R. McDonough, 1991. Synthetic Aperture Radar Systems and Signal Processing. New York: John Wiley \& Sons.

Ferretti, A., C. Prati, and F. Rocca, 2001. Permanent scatterers in SAR interferometry. IEEE Trans. on Geoscience and Remote Sensing, 39, 8-20.

Gray, R. E. and Bruhn, R. W., 1982, Subsidence above abandoned coal mines, State of the art of ground control in longwall mining and mining subsidence

Gregg, D. W., 1977, Ground subsidence resulting underground gasification of coal, LLNL UCRL 52255.

Lu, Z. \& Wicks, C., Jr., 2010. Characterizing 6 August 2007 Crandall Canyon mine collapse from ALOS PALSAR InSAR, Geomatics, Hazards and Risk, 1(1), 8593, doi:10.1080/19475701003648077.

Massonnet, D., and K. Feigl. 1998. Radar interferometry and its application to changes in the Earth's surface. Rev. Geophys., 36, 441-500.

Mellors, R. J., X. Yang, S. Hunter, J. Wagoner, W. Foxall, D. Camp, S. J. Friedmann, 2011, New Technologies for Monitoring UCG, 2011 Pittsburgh Coal Conference, Sept. 12-15, Pittsburgh, PA.

NCB 1975, SHE: Subsidence Engineers Handbook, National Coal Board, Mining Department, London. 
Ng, H. N., A, C. Hsing-Chung, K. Zhang, L. Ge, C. Rizos , M. Omura, 2009, Deformation mapping in three dimensions for underground mining using InSAR Southern highland coal field in New South Wales, Australia, International Journal of Remote Sensing

O'Connor, K.M. and E.W. Murphy 1997. TDR Monitoring as a Component of Subsidence Risk Assessment Over Abandoned Mines. Int. Journal of Rock Mechanics \& Mining Science. Vol. 34,Nos. 3-4, Paper 230.

Olness, D., The Angrenskaya Underground Coal Gasification Station, 1982, UCRL53300, Lawrence Livermore National Laboratory.

Perski, Z., 1998, Applicability of ERS-1 and ERS-2 InSAR for Land Subsidence Monitoring in the Silesian Coal mining region, Poland. International Archives of Photogrammetry and Remote Sensing, Vol. 32, No. 7 p. 555-558.

Plattner, C., S. Wdowinski, T. H. Dixon, and J. Biggs, 2010, Surface subsidence induced by the Crandall Canyon Mine (Utah) collapse: InSAR observations and elasto-plastic modeling, Geophys. J. Int., 183, 1089-1096.

Sandwell, D. ., R. . Mellors, X. Tong, M. Wei, and P. Wessel, 2011, Open radar interferometry software for mapping surface deformation, Eos Trans. AGU, 92(28), doi:10.1029/2011E0280002.

Shafirovich, E., and A. Varma, 2009, Underground Coal Gasification: A Brief Review of Current Status, Ind. Eng. Chem. Res., 48, 7865-7875.

Stow, R., and Wright, P., 1997, Mining Subsidence Land Surveying by SAR Interferometry. $3^{\text {rd }}$ ERS Symposium, Florence, Italy

Whittaker, B.N. and Reddish, D.J., 1989. Subsidence: Occurrence, prediction and control, Elsivier, Amsterdam, 528p.

Yang, X., J. Wagoner, A. Ramirez, S. Hunter, R. Mellors, D. Camp, S. J. Friedmann, 2011, Electrical Resistance Tomography for Monitoring of Underground Coal Gasification, 2011 Pittsburgh Coal Conference, Sept. 12-15, Pittsburgh, PA. 


\section{Appendix 1. SAR data processed}

Table 1. SAR Data.

\begin{tabular}{|c|c|c|c|c|c|}
\hline Name & Region & Date & Frame & Satellite & Band \\
\hline Crandall & Utah & $9 / 8 / 07$ & 780 & PALSAR & $\mathrm{L}(23 \mathrm{~cm})$ \\
\hline Crandall & Utah & $4 / 25 / 08$ & 780 & PALSAR & $\mathrm{L}(23 \mathrm{~cm})$ \\
\hline Crandall & Utah & $9 / 16 / 10$ & 780 & PALSAR & $\mathrm{L}(23 \mathrm{~cm})$ \\
\hline Crandall & Utah & $6 / 16 / 10$ & 780 & PALSAR & $\mathrm{L}(23 \mathrm{~cm})$ \\
\hline Crandall & Utah & $10 / 24 / 07$ & 780 & PALSAR & $\mathrm{L}(23 \mathrm{~cm})$ \\
\hline Crandall & Utah & $6 / 8 / 07$ & 780 & PALSAR & $\mathrm{L}(23 \mathrm{~cm})$ \\
\hline Crandall & Utah & $12 / 17 / 10$ & 780 & PALSAR & $\mathrm{L}(23 \mathrm{~cm})$ \\
\hline Crandall & Utah & $5 / 1 / 10$ & 780 & PALSAR & $\mathrm{L}(23 \mathrm{~cm})$ \\
\hline Crandall & Utah & $12 / 9 / 07$ & 780 & PALSAR & $\mathrm{L}(23 \mathrm{~cm})$ \\
\hline Crandall & Utah & $8 / 1 / 10$ & 780 & PALSAR & $\mathrm{L}(23 \mathrm{~cm})$ \\
\hline Crandall & Utah & $12 / 14 / 09$ & 780 & PALSAR & $\mathrm{L}(23 \mathrm{~cm})$ \\
\hline Majuba & S. Africa & $9 / 16 / 08$ & 630 & PALSAR & $\mathrm{L}(23 \mathrm{~cm})$ \\
\hline Majuba & S. Africa & $1 / 30 / 08$ & 630 & PALSAR & $\mathrm{L}(23 \mathrm{~cm})$ \\
\hline Majuba & S. Africa & $2 / 1 / 09$ & 630 & PALSAR & $\mathrm{L}(23 \mathrm{~cm})$ \\
\hline Majuba & S. Africa & $8 / 4 / 09$ & 630 & PALSAR & $\mathrm{L}(23 \mathrm{~cm})$ \\
\hline Majuba & S. Africa & $1 / 27 / 07$ & 630 & PALSAR & $\mathrm{L}(23 \mathrm{~cm})$ \\
\hline Majuba & S. Africa & $6 / 16 / 08$ & 630 & PALSAR & $\mathrm{L}(23 \mathrm{~cm})$ \\
\hline Majuba & S. Africa & $5 / 1 / 08$ & 630 & PALSAR & $\mathrm{L}(23 \mathrm{~cm})$ \\
\hline Majuba & S. Africa & $12 / 17 / 08$ & 630 & PALSAR & $\mathrm{L}(23 \mathrm{~cm})$ \\
\hline Majuba & S. Africa & $7 / 30 / 07$ & 630 & PALSAR & $\mathrm{L}(23 \mathrm{~cm})$ \\
\hline Angren & Uzebekistan & $9 / 25 / 04$ & 780 & ASAR & $\mathrm{C}(5 \mathrm{~cm})$ \\
\hline Angren & Uzebekistan & $5 / 8 / 04$ & 780 & ASAR & $\mathrm{C}(5 \mathrm{~cm})$ \\
\hline Angren & Uzebekistan & $5 / 28 / 05$ & 780 & ASAR & $\mathrm{C}(5 \mathrm{~cm})$ \\
\hline Angren & Uzebekistan & $9 / 10 / 05$ & 780 & ASAR & $\mathrm{C}(5 \mathrm{~cm})$ \\
\hline Angren & Uzebekistan & $6 / 21 / 08$ & 780 & ASAR & $\mathrm{C}(5 \mathrm{~cm})$ \\
\hline Angren & Uzebekistan & $6 / 2 / 07$ & 780 & ASAR & $\mathrm{C}(5 \mathrm{~cm})$ \\
\hline Angren & Uzebekistan & $7 / 26 / 08$ & 780 & ASAR & $\mathrm{C}(5 \mathrm{~cm})$ \\
\hline Angren & Uzebekistan & $7 / 17 / 04$ & 780 & ASAR & $\mathrm{C}(5 \mathrm{~cm})$ \\
\hline Angren & Uzebekistan & $8 / 30 / 08$ & 780 & ASAR & $\mathrm{C}(5 \mathrm{~cm})$ \\
\hline Angren & Uzebekistan & $6 / 17 / 06$ & 780 & ASAR & $\mathrm{C}(5 \mathrm{~cm})$ \\
\hline Angren & Uzebekistan & $1 / 7 / 07$ & 810 & PALSAR & $\mathrm{L}(23 \mathrm{~cm})$ \\
\hline Angren & Uzebekistan & $2 / 22 / 07$ & 810 & PALSAR & $\mathrm{L}(23 \mathrm{~cm})$ \\
\hline Angren & Uzebekistan & $8 / 25 / 07$ & 810 & PALSAR & $\mathrm{L}(23 \mathrm{~cm})$ \\
\hline Angren & Uzebekistan & $10 / 10 / 07$ & 810 & PALSAR & $\mathrm{L}(23 \mathrm{~cm})$ \\
\hline Angren & Uzebekistan & $1 / 10 / 08$ & 810 & PALSAR & $\mathrm{L}(23 \mathrm{~cm})$ \\
\hline Angren & Uzebekistan & $2 / 25 / 08$ & 810 & PALSAR & $\mathrm{L}(23 \mathrm{~cm})$ \\
\hline Angren & Uzebekistan & $5 / 27 / 08$ & 810 & PALSAR & $\mathrm{L}(23 \mathrm{~cm})$ \\
\hline
\end{tabular}




\begin{tabular}{|l|l|r|r|l|l|}
\hline Angren & Uzebekistan & $1 / 12 / 09$ & 810 & PALSAR & $\mathrm{L}(23 \mathrm{~cm})$ \\
\hline Angren & Uzebekistan & $8 / 30 / 09$ & 810 & PALSAR & $\mathrm{L}(23 \mathrm{~cm})$ \\
\hline Wulanchabu & China & $2 / 1 / 09$ & 75 & ASAR & $\mathrm{C}(5 \mathrm{~cm})$ \\
\hline Wulanchabu & China & $3 / 8 / 09$ & 75 & ASAR & $\mathrm{C}(5 \mathrm{~cm})$ \\
\hline Wulanchabu & China & $4 / 12 / 09$ & 75 & ASAR & $\mathrm{C}(5 \mathrm{~cm})$ \\
\hline Wulanchabu & China & $9 / 27 / 08$ & 790 & PALSAR & $\mathrm{L}(23 \mathrm{~cm})$ \\
\hline Wulanchabu & China & $11 / 12 / 08$ & 790 & PALSAR & $\mathrm{L}(23 \mathrm{~cm})$ \\
\hline Wulanchabu & China & $9 / 16 / 08$ & 810 & PALSAR & $\mathrm{L}(23 \mathrm{~cm})$ \\
\hline Wulanchabu & China & $12 / 17 / 08$ & 810 & PALSAR & $\mathrm{L}(23 \mathrm{~cm})$ \\
\hline Wulanchabu & China & $2 / 1 / 09$ & 810 & PALSAR & $\mathrm{L}(23 \mathrm{~cm})$ \\
\hline
\end{tabular}

Table 2. List of interferograms

\begin{tabular}{|c|c|c|c|c|}
\hline Area & Region & Igram start & Igram end & band \\
\hline Majuba & S. Africa & $1 / 27 / 2007$ & $7 / 30 / 2007$ & $\mathrm{~L}(23 \mathrm{~cm})$ \\
\hline Majuba & S. Africa & $1 / 27 / 2007$ & $8 / 4 / 2009$ & $\mathrm{~L}(23 \mathrm{~cm})$ \\
\hline Majuba & S. Africa & $7 / 30 / 2007$ & $8 / 4 / 2009$ & $\mathrm{~L}(23 \mathrm{~cm})$ \\
\hline Crandall & Utah & $6 / 8 / 2007$ & $9 / 8 / 2007$ & $\mathrm{~L}(23 \mathrm{~cm})$ \\
\hline Crandall & Utah & $12 / 9 / 2007$ & $5 / 1 / 2010$ & $\mathrm{~L}(23 \mathrm{~cm})$ \\
\hline Crandall & Utah & $12 / 9 / 2007$ & $6 / 16 / 2010$ & $\mathrm{~L}(23 \mathrm{~cm})$ \\
\hline Crandall & Utah & $6 / 8 / 2007$ & $12 / 14 / 2009$ & $\mathrm{~L}(23 \mathrm{~cm})$ \\
\hline Angren & Uzebekistan & $1 / 7 / 2007$ & $1 / 12 / 2009$ & $L(23 \mathrm{~cm})$ \\
\hline Angren & Uzebekistan & $2 / 22 / 2007$ & $8 / 30 / 2009$ & $\mathrm{~L}(23 \mathrm{~cm})$ \\
\hline Angren & Uzebekistan & $2 / 22 / 2007$ & $1 / 12 / 2009$ & $\mathrm{~L}(23 \mathrm{~cm})$ \\
\hline Angren & Uzebekistan & $2 / 22 / 2007$ & $8 / 25 / 2007$ & $\mathrm{~L}(23 \mathrm{~cm})$ \\
\hline Angren & Uzebekistan & $8 / 25 / 2007$ & $8 / 30 / 2009$ & $\mathrm{~L}(23 \mathrm{~cm})$ \\
\hline Angren & Uzebekistan & $8 / 25 / 2007$ & $10 / 10 / 2007$ & $\mathrm{~L}(23 \mathrm{~cm})$ \\
\hline Angren & Uzebekistan & $10 / 10 / 2007$ & $1 / 10 / 2008$ & $\mathrm{~L}(23 \mathrm{~cm})$ \\
\hline Angren & Uzebekistan & $1 / 10 / 2008$ & $2 / 25 / 2008$ & $\mathrm{~L}(23 \mathrm{~cm})$ \\
\hline Angren & Uzebekistan & $2 / 25 / 2008$ & $5 / 27 / 2008$ & $\mathrm{~L}(23 \mathrm{~cm})$ \\
\hline Angren & Uzebekistan & $1 / 12 / 2009$ & $8 / 30 / 2009$ & $\mathrm{~L}(23 \mathrm{~cm})$ \\
\hline Angren & Uzebekistan & $7 / 17 / 2004$ & $9 / 25 / 2004$ & $\mathrm{~L}(23 \mathrm{~cm})$ \\
\hline Angren & Uzebekistan & $9 / 25 / 2004$ & $9 / 10 / 2005$ & $\mathrm{~L}(23 \mathrm{~cm})$ \\
\hline Angren & Uzebekistan & $9 / 10 / 2005$ & $6 / / 17 / 2006$ & $\mathrm{~L}(23 \mathrm{~cm})$ \\
\hline Angren & Uzebekistan & $6 / 17 / 2006$ & $6 / 2 / 2007$ & $\mathrm{~L}(23 \mathrm{~cm})$ \\
\hline Angren & Uzebekistan & $6 / 2 / 2007$ & $6 / 21 / 2008$ & $L(23 \mathrm{~cm})$ \\
\hline Angren & Uzebekistan & $6 / 21 / 2008$ & $6 / 21 / 2008$ & $\mathrm{~L}(23 \mathrm{~cm})$ \\
\hline Angren & Uzebekistan & $6 / 21 / 2008$ & $8 / 30 / 2008$ & $\mathrm{~L}(23 \mathrm{~cm})$ \\
\hline Wulanchabu & China & $2 / 1 / 2009$ & $4 / 12 / 2009$ & $\mathrm{C}(5 \mathrm{~cm})$ \\
\hline Wulanchabu & China & $3 / 8 / 2009$ & $4 / 12 / 2009$ & $C(5 \mathrm{~cm})$ \\
\hline Wulanchabu & China & $9 / 27 / 2008$ & $11 / 12 / 2008$ & $\mathrm{~L}(23 \mathrm{~cm})$ \\
\hline Wulanchabu & China & $9 / 16 / 2008$ & $12 / 17 / 2008$ & $L(23 \mathrm{~cm})$ \\
\hline Wulanchabu & China & $12 / 17 / 2008$ & $2 / 1 / 2009$ & $\mathrm{~L}(23 \mathrm{~cm})$ \\
\hline
\end{tabular}

